\title{
Operationalizing multimorbidity and autonomy for health services research in aging populations - the OMAHA study
}

\author{
Martin Holzhausen ${ }^{1 *}$, Judith Fuchs ${ }^{2}$, Markus Busch², Andrea Ernert ${ }^{1}$, Julia Six-Merker ${ }^{3}$, Hildtraud Knopf ${ }^{2}$, \\ Ulfert Hapke ${ }^{2}$, Beate Gaertner ${ }^{1,2}$, Ina Kurzawe-Seitz ${ }^{2}$, Roswitha Dietzel ${ }^{1}$, Nadine Schödel ${ }^{2}$, Justus Welke ${ }^{4}$, \\ Juliane Wiskott ${ }^{2}$, Matthias Wetzstein ${ }^{2}$, Peter Martus ${ }^{1}$, Christa Scheidt-Nave ${ }^{2}$
}

\begin{abstract}
Background: As part of a Berlin-based research consortium on health in old age, the OMAHA (Operationalizing Multimorbidity and Autonomy for Health Services Research in Aging Populations) study aims to develop a conceptual framework and a set of standardized instruments and indicators for continuous monitoring of multimorbidity and associated health care needs in the population 65 years and older.

Methods/Design: OMAHA is a longitudinal epidemiological study including a comprehensive assessment at baseline and at 12-month follow-up as well as brief intermediate telephone interviews at 6 and 18 months. In order to evaluate different sampling procedures and modes of data collection, the study is conducted in two different population-based samples of men and women aged 65 years and older. A geographically defined sample was recruited from an age and sex stratified random sample from the register of residents in Berlin-Mitte (Berlin OMAHA study cohort, $n=299$ ) for assessment by face-to-face interview and examination. A larger nationwide sample (German OMAHA study cohort, $\mathrm{n}=730$ ) was recruited for assessment by telephone interview among participants in previous German Telephone Health Surveys. In both cohorts, we successfully applied a multidimensional set of instruments to assess multimorbidity, functional disability in daily life, autonomy, quality of life (QoL), health care services utilization, personal and social resources as well as socio-demographic and biographical context variables. Response rates considerably varied between the Berlin and German OMAHA study cohorts (22.8\% vs. 59.7\%), whereas completeness of follow-up at month 12 was comparably high in both cohorts (82.9\% vs. 81.2\%).

Discussion: The OMAHA study offers a wide spectrum of data concerning health, functioning, social involvement, psychological well-being, and cognitive capacity in community-dwelling older people in Germany. Results from the study will add to methodological and content-specific discourses on human resources for maintaining quality of life and autonomy throughout old age, even in the face of multiple health complaints.
\end{abstract}

\section{Background}

Multimorbidity, e. g. the concurrent existence of multiple health problems in the same person, is a highly prevalent phenomenon in old age and of growing public health impact in aging societies [1-3]. The terms multimorbidity and comorbidity have been used interchangeably. In fact, comorbidity is the older concept and was

\footnotetext{
* Correspondence: martin.holzhausen@charite.de

'Charité - Universitätsmedizin Berlin, Charitéplatz 1, D-10117 Berlin, Germany Full list of author information is available at the end of the article
}

first introduced by Feinstein who demonstrated that comprehensive assessment of concomitant health problems among patients with a particular index disease is crucial to explain differences in therapeutic outcome [4].

Due to methodological challenges and limited epidemiological data, the prevalence, patterns, determinants, correlates, and consequences of multimorbidity are not well researched [5,6]. A first and major challenge lies in the definition of multi- and comorbidity itself. There is no consensus yet as to which health conditions should be considered and how exactly they should be assessed,

\section{Ciomed Central}


summarized and weighted in order to arrive at some overall measure of burden of illness. Apart from quantitative aspects, the type and patterns of concurrent morbidities will matter with respect to treatment options and prognosis. A second challenge relates to measuring the impact of multi- and comorbidity $[7,8]$. As many of the health complaints people face in old age are chronic and progressive, and as multiple concurrent conditions are known to interact, measures of disease-specific treatment success, such as 'cure' or reduction in some surrogate measure may not be appropriate. The focus of geriatric outcome research is hence on functional measures, such as critical exhaustion of specific body functions (often termed as 'frailty'), functional disability in daily life, and social participation on one hand and on subjective measures, such as quality of life (QoL) and self-determination (autonomy) on the other $[9,10]$. However, there is an ongoing debate within health sciences on how to define these constructs, and on which instruments should be used to assure standardized assessment and comparability of study results [11-13]. A third and not too minor challenge lies in the fact that the relationship between multimorbidity and various outcomes is likely to be modified by a number of medical as well as non-medical resources and risk-factors. This concept has been referred to as patient complexity [14]. Examples for personal resources relevant to maintain autonomy and quality of life despite functional impairment and reduced health status include health-related knowledge, beliefs, competences, and proactive behaviour [15]. External resources include perceived social support, living conditions, and quality of health care [14]. Beyond that, context variables such as socio-demographic and cultural background as well as critical life events at personal or societal level need to be considered [16,17].

Against this background, the Federal Ministry of Education and Research (BMBF) launched a long term research initiative on 'Health in Old Age'. A total of six research consortia qualified for an initial three-year funding period (2008-2010) to provide insight into the epidemiology and socioeconomic consequences of multimorbidity in older people in Germany [18]. Among these, the Berlin-based consortium Autonomy Despite Multimorbidity in Old Age (AMA) focuses on resources and potentials to maintain everyday-functioning and self-determination of older people with multiple health constraints [19].

The population-based AMA subproject OMAHA (Operationalizing Multimorbidity and Autonomy for Health Services Research in Aging Populations) aims to develop a conceptual framework and a set of standardized instruments and indicators for continuous monitoring of multimorbidity and associated health care needs in the population 65 years and above. Main specific goals are: (1) to develop an algorithm for the comprehensive assessment of multi- and comorbidity, (2) to analyze patterns, correlates, determinants, and consequences of multi- and comorbidity; (3) to evaluate an innovative instrument for preference-based QoL assessment among elders with multimorbidity; (4) to examine the effectiveness and efficiency of different recruitment strategies and to characterize difficult-to-reach subgroups of the population 65 years and older. We describe here the design, methods, study population, and data base of the OMAHA study.

\section{Methods/Design \\ Study design}

The OMAHA study is designed as a population-based longitudinal epidemiological study of multimorbidity in the population aged 65 years and older. With regard to methods applied for continuous nationwide health monitoring in Germany [20], the OMAHA project uses two different modes of data collection and sampling frames: (1) assessment by standardized computer-assisted personal interview (CAPI) and examination in a geographically defined population sample of men and women 65 years and older residing in the inner district of Berlin (BerlinMitte) as of July 15, 2008; (2) assessment by standardized computer-assisted telephone interview (CATI) in a nationwide population sample of men and women aged 65 years and older who participated in previous German Health Telephone Surveys and had agreed to be re-contacted. In each case, the study protocol consisted of a comprehensive assessment at baseline and at 12-month follow-up. In addition, short intermediate telephone follow-up interviews for assessment of vital and functional status were conducted at month 6 and 18 .

The study was approved by the local ethics committee at Charité - Universitätsmedizin Berlin and conducted in compliance with data protection and privacy regulations as requested by the Federal and Berlin Offices for the Protection of Data. Study participants were informed in detail about the study objectives, interview and examination procedures as well as pseudonymized record keeping and subsequent data analysis. Persons participating in the personal interview and examination gave written informed consent prior to study inclusion. A subset also provided written permission to contact their family doctor for validation of specific self-reported medical conditions (e. g., ischemic heart disease, diabetes, asthma, chronic bronchitis). Oral informed consent to study participation was obtained from participants in previous German health telephone surveys before conducting the OMAHA baseline CATI.

\section{Sampling procedures and recruitment of study participants}

For the Berlin OMAHA cohort, we drew an age (65-69, 70-74, 75-79, 80-84, 85+ years) and sex stratified random 
sample of 2000 men and women aged 65 years and older from the official register of residents in Berlin-Mitte as of July 15, 2008. All individuals of the population sample who were then verified as alive, still living in Berlin-Mitte and available during the study recruitment period were eligible for the study. Exclusion criteria were: death, permanent change of residence outside of Berlin-Mitte or to an unknown address, and continuous absence from Berlin during study recruitment period. Anticipating an overall response rate of about $20 \%$ and an overall proportion of unverifiable contacts of 5-10\%, the total sample size was sufficiently large to achieve a study population of $n=300$ for the main study and of $n=100$ for preceding pre-test evaluation.

To assure public support of the study, we communicated the study goals and logistics to members of the Berlin Medical Association via the official journal of the Berlin Medical Association (Anonymous, 2009) and to community officials (e. g., local police stations, churches) via telephone contacts.

Individuals belonging to the main sample were initially contacted by post. The letters contained a brief description of the study, an invitation to participate, and a prepaid self-addressed envelope together with a return sheet to fill in telephone numbers, preferred contact times, and choice of home or study centre visit for the assessment. Participants were offered a small monetary incentive $(€ 10)$ plus reimbursement for travel expenses. Foreign nationals were offered a brief description of the study in seven different languages (Turkish, Russian, Arabic, Serbian, Croatian, Polish, and English).

In order to identify and further characterize persons who did not participate, we explicitly asked family members or caregivers to respond in case that an eligible person was not able to participate due to cognitive impairment or severe illness and to consent to proxy telephone interviews.

Among persons who did not respond to the initial mailed invitation, we conducted a randomized controlled trial which evaluated the effectiveness and efficiency of three different intensified recruitment strategies: (a) personal visits, (b) telephone calls, or (c) mailed reminder letters including the initial invitation letter and enclosures. Statistical analysis of this comparative evaluation of recruitment strategies is completed and results are currently prepared for publication in a separate paper.

The German OMAHA cohort was recruited from a pool of persons who had previously participated in the German Telephone Health Surveys 2004 or 2006. Nationwide telephone health surveys have been conducted in Germany annually by the Robert Koch Institute since 2002/2003; sampling procedures and recruitment strategies have been previously described in detail [21].
In brief, telephone numbers from complete listings of landline telephone connections belonging to private households in Germany are randomly generated, applying the Gabler-Häder method [22]. This method assures that households with unregistered telephone numbers are included in the 'target sample' of telephone surveys. Random sampling at the individual level is achieved by the 'next-birthday-method', i.e. only the adult whose birthday is coming up next to the date of first contact to the respective household is included in the target sample. Automated redialling systems and computer-assisted interviewer guidance assure that telephone contact and interview procedures are conducted in a highly standardized and efficient way. In the 2004 and 2006 German Telephone Health Surveys, $56.1 \%$ and $56.6 \%$ of contacted persons 18 years of age and older completed the survey (3376 men; 3965 women in 2004 [23]; 2682 women and 2860 men in 2006 [24]). The majority of survey participants 65 years and older $(n=1263$ or $87.4 \%$ in 2004, and $n=846$ or $86.0 \%$ in 2006 ) consented to be recontacted by the Robert Koch Institute for future health surveys. Excluding n = 557 persons who were part of a random sample included in a European telephone health survey, a total of $\mathrm{n}=1552$ men and women remained to be re-contacted for the OMAHA baseline telephone assessment.

\section{Response and analysis of non-response bias}

Of the total Berlin sample, 519 persons (26.0\%) had initially been contacted for preceding pre-test evaluation, leaving a total of $\mathrm{n}=1481$ persons for the main study (Figure 1). Of these, 173 persons (11.7\%) were excluded as they had died $(n=68)$, had changed residence $(n=85)$, or were absent during the entire recruitment period $(n=20)$. Of the 1308 eligible persons, 299 (22.9\%) participated in the study and completed the full baseline assessment between January and June 2009. Among 1009 non-participants, $\mathrm{n}=384$ (38.1\% of nonparticipants) declined full assessment but completed a short questionnaire (also available in the seven different languages mentioned above) covering self-rated health, limiting longstanding illness, disability, care dependency, living arrangements and marital status; $\mathrm{n}=324(32.1 \%$ of non-participants) declined both full assessment and short questionnaire; and $\mathrm{n}=301$ (29.8\%) did not respond to all our contacts. The short questionnaires were administered via standardized telephone interview or self-administered postal questionnaires which were returned in a self-addressed prepaid envelope. Among $\mathrm{n}=296$ participants surviving to the 6-month-followup, $\mathrm{n}=291$ (98.3\%) completed the brief 6-month follow-up questionnaire delivered by standardized telephone interview. The 12-month follow-up assessment was conducted between January and April 2010 and is 


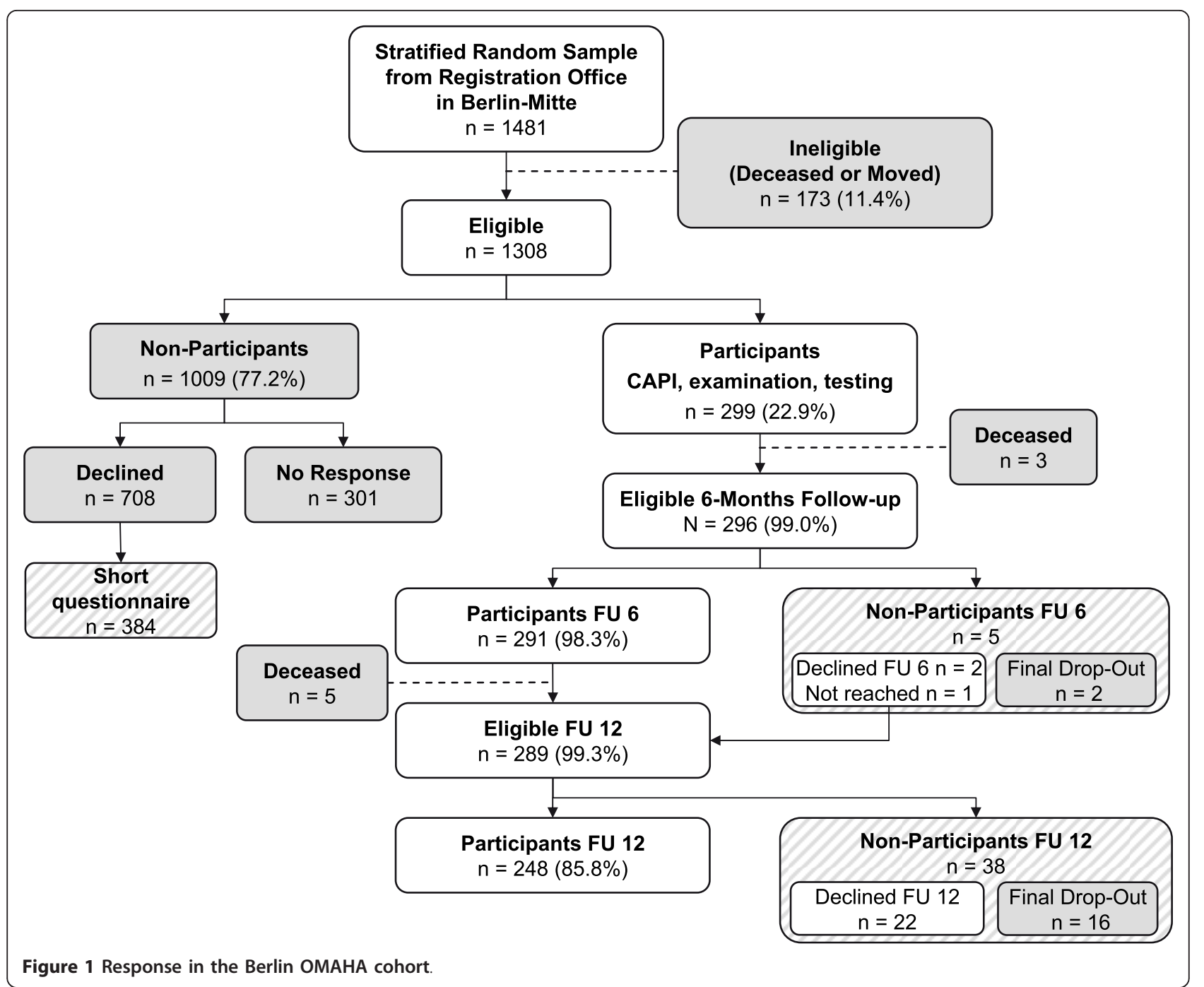

complete for $\mathrm{n}=248$ (85.2\% of 291 participants surviving to 12 months). The concluding 18-month telephone follow-up was completed in October 2010 for $n=262$ participants $(91.0 \%$ of 288 participants surviving to month 18).

For preceding pre-test evaluation, a random sample of $\mathrm{n}=100$ stratified by sex and five age groups (65-69, 70$74,75-79,80-84,85+$ years) was drawn from the German Telephone Health Survey sample 2007 [25].

$\mathrm{N}=1552$ participants in previous German Telephone Health Surveys 2004 and 2006 were selected for the OMAHA study (Figure 2), 329 persons (21.2\%) were excluded because they had died or their telephone numbers were found to be disconnected. Of the remaining 1223 persons, 730 (59.7\%) completed the OMAHA baseline assessment via computer-assisted telephone interview (CATI) between March and April 2009. Among non-participants, the majority $(\mathrm{n}=334)$ refused to participate, while some persons $(n=23)$ started but did not complete the telephone interview, and $\mathrm{n}=135$ (27.5\%) could not be reached during the baseline study period. Of baseline participants, $n=670$ (91.8\%) completed the brief 6-month telephone follow-up, administered via CATI. Among the 60 persons not continuing into follow-up, 5 had died in the interim, 30 refused to participate (11 stating that decision directly after baseline assessment), and 25 could no longer be reached by the given telephone number. The full 12-month followup assessment was conducted in May and June 2010 and was completed for $\mathrm{n}=593(81.2 \%)$ of OMAHA baseline study participants (Figure 2). The concluding 18-month telephone follow-up is currently underway and will be completed by January 2011.

Non-response analyses will be conducted based on comparisons of key health and socio-demographic characteristics between participants and non-participants. For the nationwide cohort such information can be extracted from data collected during previous German 


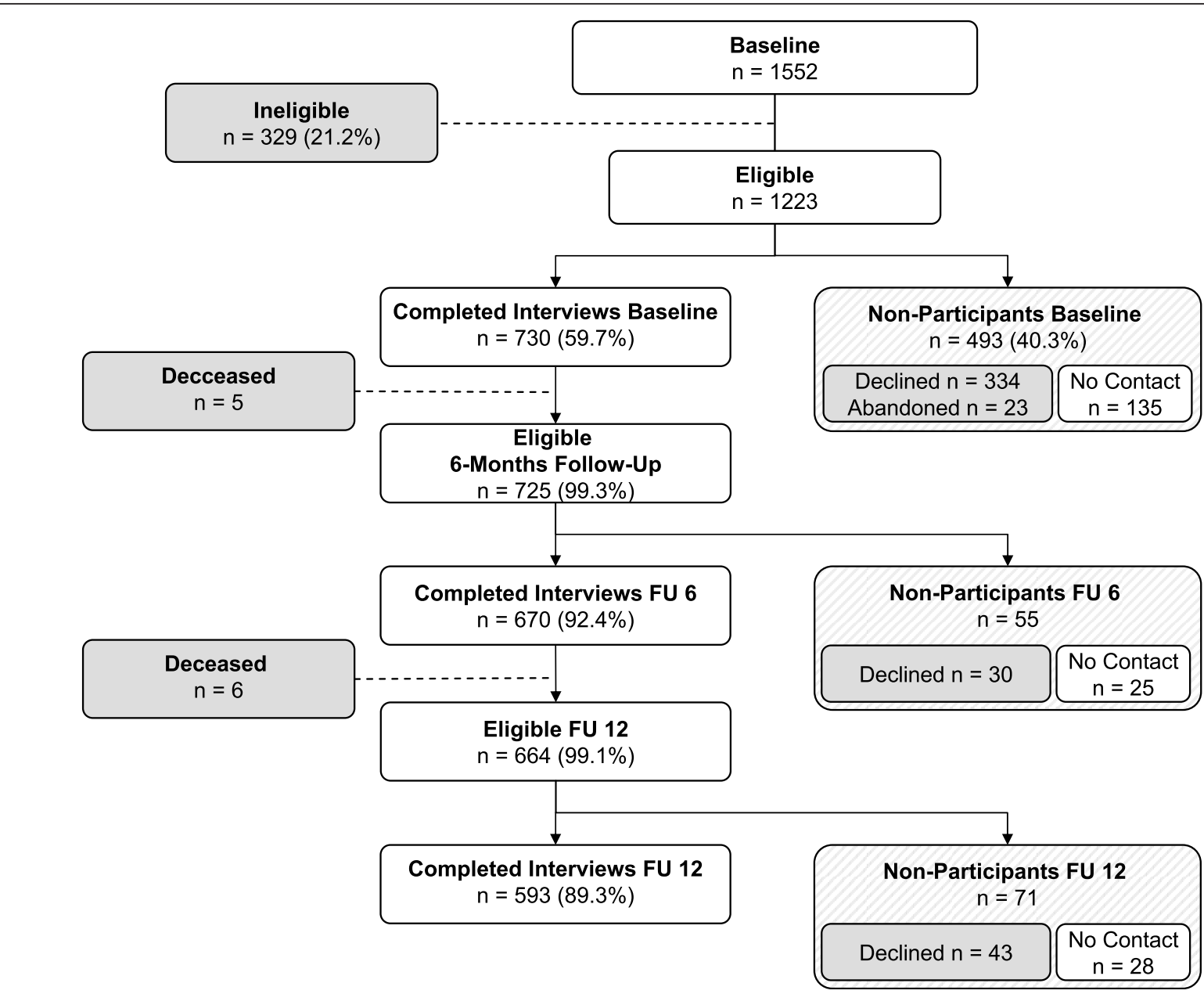

Figure 2 Response in the German OMAHA cohort

Telephone Health Survey contacts [23,24]. In the Berlin cohort, information on age, sex, nationality, nursing home residence, and area deprivation score was available from the dataset provided by the residents registration office in Berlin-Mitte and official social statistics for the city of Berlin. Further comparisons between participants and non-participants with respect to health and disability as well as social networks and care dependence will be limited to the $38 \%$ subset of non-participants who answered a brief questionnaire for baseline assessment.

\section{Constructs and instruments}

Within the conceptual framework depicted in Figure 3, we selected and composed a set of instruments that would permit to provide valid, reliable, and efficient measures of (a) multimorbidity, (b) potential consequences of multimorbidity, including impairment of body functions and frailty, autonomy, quality of life, and health care services utilization, (c) personal and social resources likely to modify the association between multimorbidity and outcome measures, (d) socio-demographic and biographical context variables.

Selection of instruments was based on extensive literature review and feasibility pre-testing. Table 1 provides an overview of the main theoretical constructs, construct domains, and instruments. Assessment tools were aligned as closely as possible between the two OMAHA study arms (Berlin cohort and German cohort). Nevertheless, constructs covered and instruments used for their measurement differed to some degree according to the different assessment modes.

The theoretical construct of multimorbidity is composed of two domains: (a) health status as assessed by self-reported physician-diagnosed health conditions, history of surgical procedures, history of fractures past age 50 years, medication use within 7 days prior to the interview, and standardized measures (Berlin cohort only) of height, weight, waist and calf circumference, and blood pressure; (b) self-reported current symptoms and complaints including sensory limitations (vision 


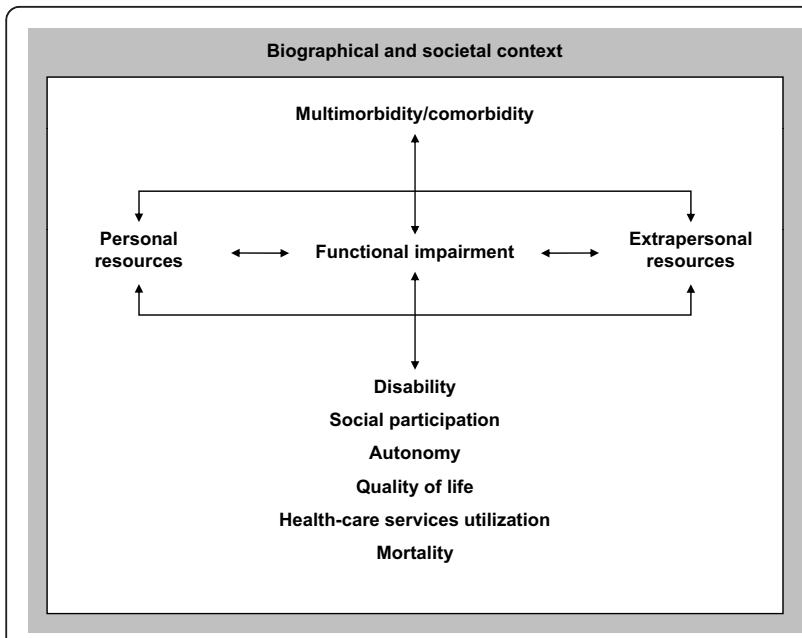

Figure 3 Framework of the OMAHA Study.

and hearing problems), urinary and faecal incontinence, constipation, back pain, and joint complaints. Overall, 31 specific health conditions were covered in the CAPI and CATI following a standardized sequence of questions on first and last time of occurrence of symptoms, medical treatment within the past 12 months, and perceived level of condition specific limitation in daily life (Figure 4). Current symptoms of depression as assessed by the Patient Health Questionnaire (PHQ) were used as an indicator of mental health. Operations, falls (only Berlin cohort), and health services utilization were also assessed. Functional assessment covered (a) a short neuropsychological test battery, (including tests of orientation, episodic memory, verbal fluency, and psychomotor speed) and (b) standardized measures of physical functioning (including measures of grip strength, balance, and lower extremity dysfunction. The digit symbol substitution test (DSST) and physical functioning tests were restricted to the Berlin OMAHA study cohort. Conceptualizing frailty as a critical exhaustion of specific body functions or combinations of body functions we used previously published cut-off levels [26-29]. In this context, self-reported weight loss within the past 12 months, height loss since age 25 years, and history of falls within the past 12 months and the past four weeks were also assessed.

Standardized anthropometric measurements and automated assessment of current medication use were limited to the Berlin OMAHA study cohort. A complete inventory of all medications used within 7 days prior to the interview (including prescriptions as well as non-prescription drugs) was assured by scanning the original containers brought to the examination site for that purpose. All drugs were automatically coded by an underlying software system to the WHO-ATC system. Details on medication use also included self-reported indications, form of administration, frequency of intake, origin of the medicine, and duration of use.

Autonomy is conceptualized twofold as (a) absence of disability in daily life and dependence on care, and (b) perceived self-determination. Disability and dependence on care were assessed by standardized CAPI or CATI, covering questions on limitations in activities of daily living (ADL, IADL), and everyday competence. Questions on subjective self-determination were covered in the self-administered questionnaire and are hence limited to the Berlin cohort.

Quality of life comprises the following domains: selfrated health, subjective well-being and vitality, pain, health-related QoL, global life satisfaction, and preference-based quality of life. All of these except preference-based quality of life were assessed in both OMAHA cohorts by validated instruments via standardized interview (CAPI or CATI) or self-administered questionnaire. Preference-based QoL was assessed only in the Berlin cohort by the newly developed tool FLQM ('Fragebogen zur Lebensqualität multimorbider älterer Menschen') as part of the CAPI. Additional instruments to measure global life satisfaction (Satisfaction with Life Scale, SWLS) and subjective well-being (International Positive and Negative Affect Schedule, IPANAS) were administered in the Berlin cohort only.

Resources can roughly be divided into personal, social and organizational resources. As facets of personal resources, individual health-related behaviours (alcohol consumption, nutrition, tobacco use, physical activity), educational status, and income as well as housing and environment were assessed in both OMAHA cohorts by standardized self-administered questionnaire or CATI. Proactive coping as another important personal resource was assessed by the Proactive Coping Inventory (PCI) via self-administered questionnaire in the Berlin cohort only, since the PCI is not suitable for administration via CATI. As part of the social resource domain, social contacts were assessed in both OMAHA cohorts by the same validated instrument (MILVA). In lack of a validated instrument for administration by CATI, the assessment of subjective social support (by BSSS) was restricted to the Berlin OMAHA cohort. Organizational resources assessed were health insurance, family doctor, housing and environment, and nursing care level within the German healthcare system. Additional context variables covered age, critical life events, and migration background.

\section{Power analysis}

Due to the exploratory nature of the study and the multiplicity of outcomes, no power calculation was considered. 
Table 1 Constructs, facets, and measurement tools in OMAHA

\begin{tabular}{|c|c|c|c|}
\hline Theoretical Construct and Facets & Measure & $\begin{array}{l}\text { Berlin } \\
\text { cohort }\end{array}$ & $\begin{array}{l}\text { German } \\
\text { cohort }\end{array}$ \\
\hline \multicolumn{4}{|l|}{ Multimorbidity } \\
\hline Long-standing or chronic disease & Minimum European Health Module (MEHM)[31,32] & $\mathrm{PI}$ & $\mathrm{Tl}$ \\
\hline Diseases and health problems & $\begin{array}{l}\text { Closed-ended questions on medical conditions and health problems (cf. Figure } \\
\text { 2) }{ }^{a}\end{array}$ & $\mathrm{Pl}$ & $\mathrm{Tl}$ \\
\hline Operations & $\begin{array}{l}\text { Open-ended questions for surgery since age } 40 \text {, followed by closed-ended } \\
\text { questions }{ }^{\text {a }}\end{array}$ & $\mathrm{Pl}$ & $\mathrm{Tl}$ \\
\hline Regular medication & Closed-ended question a & $\mathrm{Pl}$ & $\mathrm{Tl}$ \\
\hline Depression & Patient Health Questionnaire (PHQ2/9)[33,34] & $\mathrm{Pl}$ & $\mathrm{Tl}$ \\
\hline Medication & Barcode scanning and assessment of currently used medication[20] & $\mathrm{Pl}$ & - \\
\hline Falls & Closed-ended questions according to[35] & $\mathrm{Pl}$ & $\mathrm{Tl}$ \\
\hline Fractures & List $^{a}$ & $\mathrm{PI}$ & - \\
\hline Medical care & According to German National Health Interview and Examination Survey[30] & SQ & $\mathrm{Tl}$ \\
\hline Blood pressure & Blood pressure meter ${ }^{b}$ & $\mathrm{Pl}$ & - \\
\hline Weight & Electronic scales ${ }^{c}$ & $\mathrm{Pl}$ & - \\
\hline Height & Portable stadiometer ${ }^{d}$ & $\mathrm{Pl}$ & - \\
\hline Circumference of waist, calf, arm & Flexible measuring tape ${ }^{e}$ & $\mathrm{PI}$ & - \\
\hline \multicolumn{4}{|l|}{ Quality of Life } \\
\hline Self-rated overall health & Minimum European Health Module (MEHM; also question 2 in SF-36)[31,32] & $\mathrm{Pl}$ & $\mathrm{Tl}$ \\
\hline Global life-satisfaction & Single question ${ }^{a}$ & $\mathrm{Pl}$ & $\mathrm{Tl}$ \\
\hline Global life-satisfaction & Satisfaction With Life Scale (SWLS)[36] & $\mathrm{PI}$ & - \\
\hline Global life-satisfaction & Fragebogen zur Lebensqualität multimorbider älterer Menschen (FLQM)[37] & $\mathrm{PI}$ & - \\
\hline Subjective well-being & International Positive and Negative Affect Schedule (IPANAS)[38,39] & $\mathrm{Pl}$ & - \\
\hline Comparative self-rated overall health & Closed-ended questions ${ }^{\text {a }}$ & SQ & - \\
\hline Health-related quality of life & $E Q-5 D[40,41]$ & SQ & $\mathrm{Tl}$ \\
\hline Subjective well-being & Vitality sub-scale of SF-36[42,43] & SQ & $\mathrm{Tl}$ \\
\hline Pain & Questions 7 and 8 of SF-36; adapted time-frame[42,43] & SQ & $\mathrm{Tl}$ \\
\hline
\end{tabular}

\section{Autonomy}

Limitations due to health problem

Need for assistance

Functional health I: ADL

Functional health I: IADL

Functional health II: Functional limitations

Autonomy
Minimum European Health Module (MEHM)[31,32]

Closed-ended questions modified from[44]

According to Katz[45,46]

According to Lawton \& Brody[47,48]

Closed-ended questions adapted from[32]

Wahrgenommene Autonomie im Alter (WAA)[49]

$\begin{array}{cc}\text { PI } & \text { TI } \\ \text { PI } & \text { TI } \\ \text { PI } & \text { TI } \\ \text { PI } & \text { TI } \\ \text { SQ } & \text { TI }\end{array}$

SQ

\section{Resources (incl. Socio-Demography) and Performance Tests}

Year of birth

Gender

Marital status

Education and employment

Net household income

Household size

Number of and contact with children

Religion

Migration

Health insurance

Nursing care level

Housing and environment

Social contacts

Social support
According to German National Health Interview and Examination Survey[30]

According to German National Health Interview and Examination Survey[30]

According to German National Health Interview and Examination Survey[30]

According to German National Health Interview and Examination Survey[30]

According to German National Health Interview and Examination Survey[30]

Closed-ended questions [24]

Closed-ended questions[44]

Closed-ended question [50]

According to Schenk et al.[51]

According to German National Health Interview and Examination Survey[30]

Closed-ended question ${ }^{\text {a }}$

Mannheimer Inventar der Lebensverhältnisse im Alter (MILVA), subscale, housing'[52]

Mannheimer Inventar der Lebensverhältnisse im Alter (MILVA), subscale, contacts'[52]

Berliner Social Support Scales (BSSS)[53]

$\begin{array}{ll}\text { PI } & \text { TI } \\ \text { PI } & \text { TI } \\ \text { PI } & \text { TI } \\ \text { PI } & \text { TI } \\ \text { PI } & \text { TI } \\ \text { PI } & \text { TI } \\ \text { PI } & \text { TI }\end{array}$

PI TI

$\mathrm{PI} \quad \mathrm{TI}$

SQ $\quad$ -

$\mathrm{PI} \quad \mathrm{TI}$

SQ TI

SQ TI

SQ 
Table 1 Constructs, facets, and measurement tools in OMAHA (Continued)

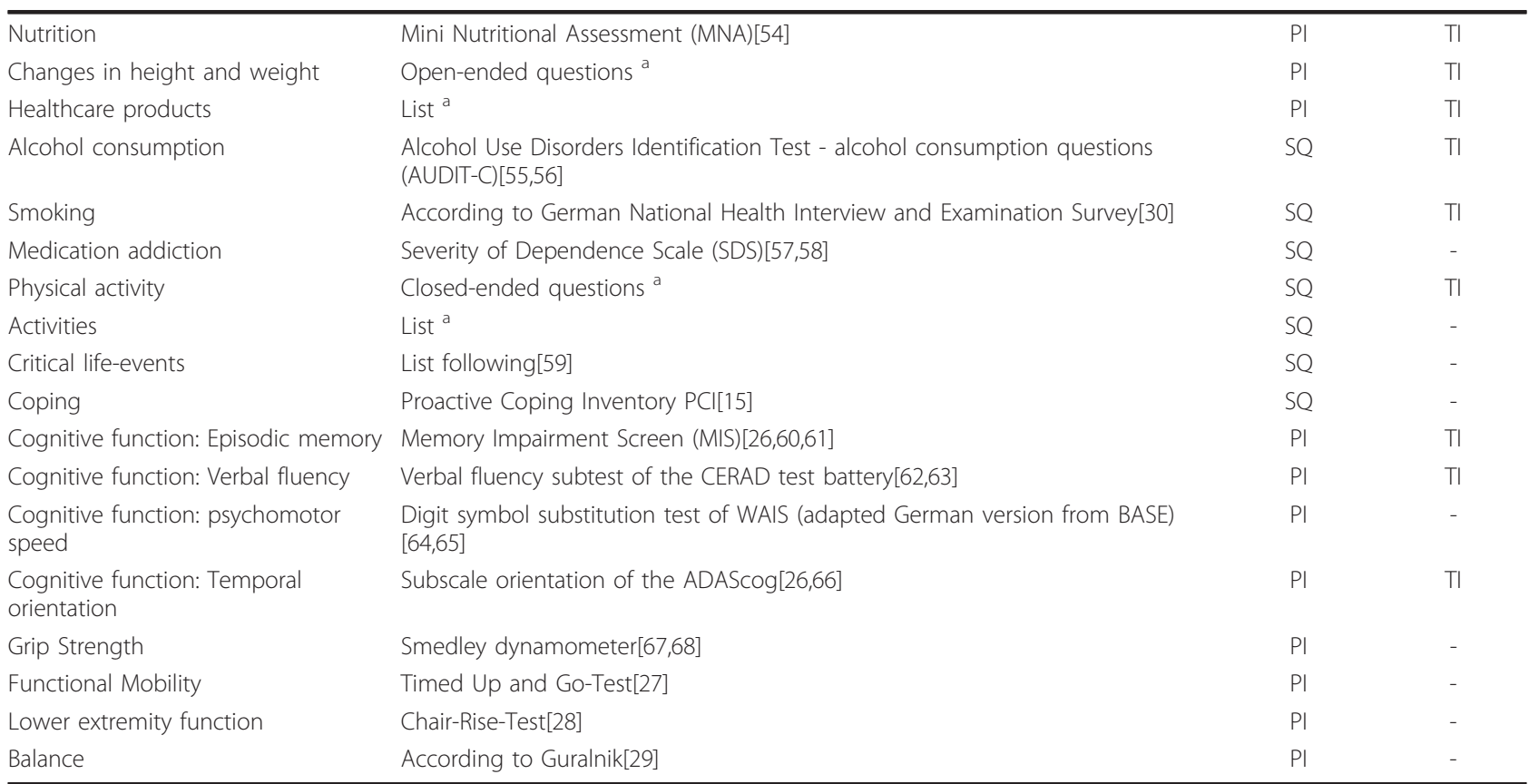

$\mathrm{PI}=$ personal interview/assessment; $\mathrm{SQ}=$ self-complete questionnaire; $\mathrm{TI}$ = telephone interview.

${ }^{\text {a }}$ Self-developed questionnaire.

b Datascope Accutor Plus, the Netherlands.

c SECA, Germany, accuracy of measurement $0.1 \mathrm{~kg}$.

${ }^{\mathrm{d}}$ Holtain Ltd., UK, accuracy of measurement $0.1 \mathrm{~cm}$.

e Hoechstmass, Sulzbach, Germany, accuracy of measurement $0.1 \mathrm{~cm}$.

\section{Data management and preparation for analysis}

A statistician supervised, validated, and where necessary corrected the data throughout the process of data-collection. Cleaned final data sets were provided by the statistician within less than 6 months after the completion of data collection. A detailed documentation of the process was continuously accessible to the research team.

\section{Quality assurance}

To achieve a high degree of standardization in the survey, the study nurses for personal interviews (CAPI) were initially trained and continuously supervised. Additional training sessions took place before the 12-months follow-up. Telephone interviewers were highly experienced in carrying out telephone health surveys and received specific training before the baseline interview as well as before the 6-month and 12-month follow-up interviews. Standard operation procedures (SOPs) were supplied for all parts of the computer-assisted interviews (CAPI and CATI), functional assessments, and anthropometric measurements. Quality standards and requirements for internal quality control were developed according to recognized epidemiological guidelines and standards applied in German Health Interview and Examination Surveys [30].

\section{Discussion}

The OMAHA project is a longitudinal epidemiological study in two population-based cohorts of older people aged 65 years or older using different methods of data collection. In the urban cohort (Berlin cohort), an ageand sex-stratified sample of residents of an inner-city district of Berlin was assessed by face-to-face interviews, self-administered questionnaires and measurement of physical functions and body measures. In the nationwide cohort (German cohort), participants of former German Health Telephone Surveys were assessed by telephone interview.

Our research is focused on the development of a comprehensive assessment of multi- and comorbidity and the analysis of patterns, correlates, determinants, and consequences of these. Also, an innovative instrument for preference-based QoL assessment among elders suffering from multimorbidity will be evaluated. On the methodological level, we examine the effectiveness and efficiency of different recruitment strategies and will characterize difficult-to-reach subgroups of the population 65 years and older. Data collection comprises four waves in each of the two cohorts: two more extensive waves at baseline and 12-month follow-up, and two very brief waves at months 6 and 18 from baseline assessment. This opens 


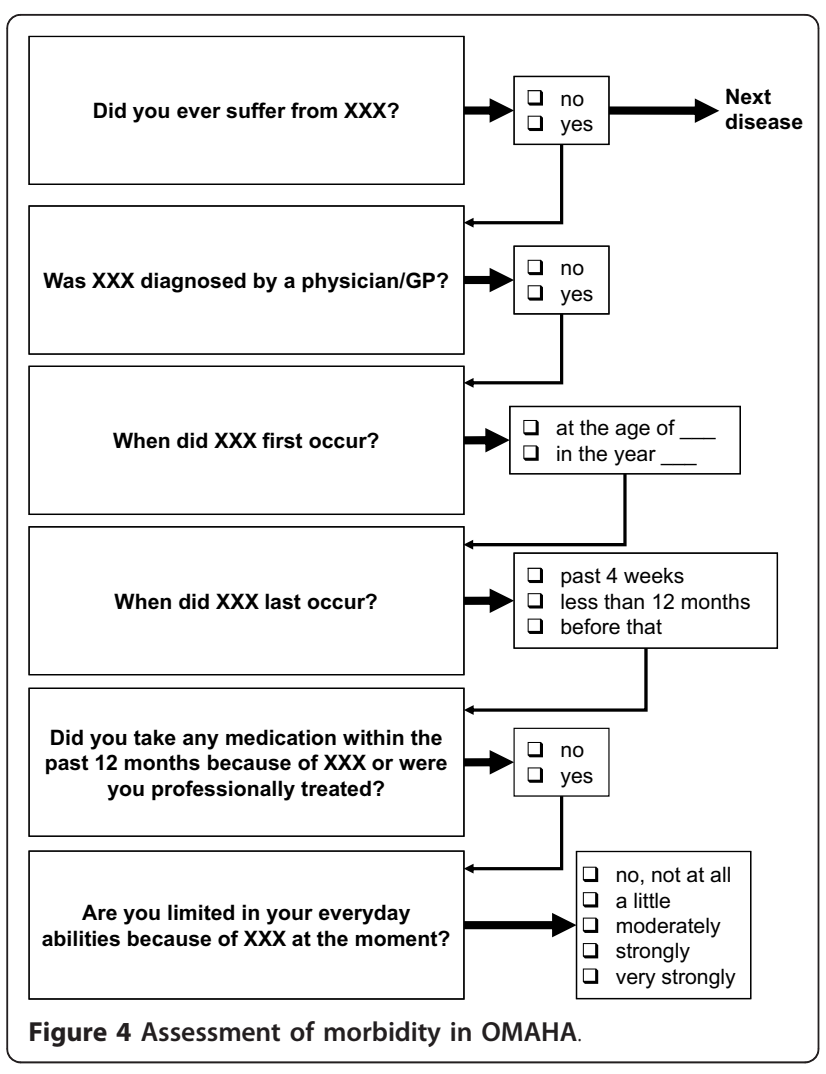

up a wide range of opportunities for analyses on trajectories of health states, longitudinal relationships of outcome determinants, and, most importantly, causal relationships between conditions and trajectories over a period of 18 months.

The parallel application of instruments in the two cohorts and modes of administration (CAPI and CATI) will on the one hand allow us to identify those tools that are most suitable for telephone administration. On the other hand, we will also be able to make comparisons between the urban Berlin cohort and the nationwide cohort with respect to selected variables crosssectionally as well as longitudinally. The wide variety of measures relating to similar constructs allows us to soundly determine the psychometric properties of adaptations and new developments for geriatric and gerontological assessments in older age groups. After the completion of analyses relating to validity and reliability of (1) adaptations of existing measurement tools and (2) the newly developed quality of life assessment tool (FLQM) we will be able to provide a wide-ranged set of instruments and tools for personal and telephone assessment in population-based health surveys.

Clearly, the samples are subject to selective inclusion. Within the Berlin cohort, there were considerable differences in sample structure with respect to different major sub-populations, such as migrants or people living in nursing-homes and socio-economically deprived areas. In addition to the specified sub-populations, people suffering from dementia or cognitive impairment and those who are heavily restricted in their sensory capacity are not likely to be adequately represented in both cohorts. Because determining barriers and evaluating recruitment strategies are among our goals, we did not expect the participating sample to be representative. In contrast, analyses of the effectiveness and efficiency of the three different recruitment strategies in the Berlin cohort and detailed analysis of participant/non-participant characteristics in both cohorts will enable us to derive strategies on how to get better access to, and response from, these groups. In future studies, a strategy of oversampling underrepresented, yet notably prevalent and politically important groups could serve as one means to minimize selection bias.

OMAHA offers a wide spectrum of data related to health, functioning, social involvement, psychological well-being, and cognitive capacity throughout old age in Germany, opening up new opportunities for further gerontological and geriatric research. Results from the study will add to methodological as well as content-specific discourses on human resources for maintaining high levels of autonomy and quality of life in old age, even in the face of multiple health burdens and morbidity.

\section{Acknowledgements}

The project described in this article is funded by the Federal Ministry of Education and Research under Grant Number 01ET0701. It has been approved by the local ethics committee under approval number EA2/066/08. The contents of this publication are solely the responsibility of the authors.

\section{Author details}

${ }^{1}$ Charité - Universitätsmedizin Berlin, Charitéplatz 1, D-10117 Berlin, Germany. ${ }^{2}$ Robert Koch Institute, General-Pape-Str. 62-66, D-12101 Berlin, Germany. ${ }^{3}$ Universitätsklinikum Freiburg, Sektion Tumorepidemiologie, Elsässerstr. 2, D79110 Freiburg, Germany. ${ }^{4}$ Gemeinsamer Bundesausschuss, Wegelystraße 8, D-10623 Berlin, Germany.

\section{Authors' contributions}

$\mathrm{MH}$ and CSN conceptualized and supervised the study, analyzed the data and wrote the final manuscript. JF, MB and PM conceptualized and supervised the study, analyzed the data and made substantial contributions to the writing of the final manuscript. JWelke, JSM, HK, UH assisted in the conceptualization of the study, provided specific knowledge, made substantial contributions to the acquisition and quality assurance of the data and contributed to the final manuscript. RD, NS, IKS, JWiskott provided specific knowledge, made substantial contributions to the acquisition and quality assurance of the data and contributed to the final manuscript. AE assisted in the conceptualization of the study, analyzed the data and contributed to the final manuscript. BG analyzed the data and contributed to the final manuscript. MW made substantial contributions to the acquisition and quality assurance of the data and contributed to the final manuscript.

\section{Competing interests}

The authors declare that they have no competing interests.

Received: 31 December 2010 Accepted: 25 February 2011

Published: 25 February 2011 


\section{References}

1. Anderson G, Horvath J: The growing burden of chronic disease in America. Public Health Reports 2004, 119:263-270.

2. Fortin M, Soubhi $H$, Hudon C, Bayliss EA, van den Akker M: Multimorbidity's many challenges - time to focus on the needs of this vulnerable and growing population. British Medical Journal 2007, 334:1016-1017.

3. State of World Population. 2009 [http://www.unfpa.org/swp/2009/en/]

4. Feinstein AR: The pre-therapeutic classification of co-morbidity in chronic disease. Journal of Chronic Diseases 1970, 23:455-468.

5. Fortin M, Hudon C, Haggerty J, van den Akker M, Almirall J: Prevalence estimates of multimorbidity: a comparative study of two sources. BMC Health Services Research 2010, 10:111.

6. Scheidt-Nave C, Richter S, Fuchs J, Kuhlmey A: Challenges to health research for aging populations using the example of "multimorbidity". Bundesgesundheitsblatt Gesundheitsforschung Gesundheitsschutz 2010, 52:441-450.

7. de Groot V, Beckerman H, Lankhorst GJ, Bouter LM: How to measure comorbidity. a critical review of available methods. Journal of Clinical Epidemiology 2003, 56:221-229.

8. van den Akker M, Buntinx F, Roos S, Knottnerus JA: Problems in determining occurrence rates of multimorbidity. Journal of Clinical Epidemiology 2001, 54:675-679.

9. Kaplan RM: The significance of quality of life in health care. Quality of Life Research 2003, 12(Suppl 1):3-16

10. Fortin M, Bravo G, Hudon C, Lapointe L, Almirall J, Dubois MF, Vanasse A: Relationship between multimorbidity and health-related quality of life of patients in primary care. Quality of Life Research 2006, 15:83-91.

11. Haywood KL, Garratt AM, Fitzpatrick R: Quality of life in older people: a structured review of generic self-assessed health instruments. Quality of Life Research 2005, 14:1651-1668.

12. Hunt SM: The problem of quality of life. Quality of Life Research 1997, 6:205-212

13. Moons P, Budts W, De Geest S: Critique on the conceptualisation of quality of life: A review and evaluation of different conceptual approaches. International journal of Nursing Studies 2006, 43:891-901.

14. Valderas JM, Starfield B, Sibbald B, Salisbury C, Roland M: Defining comorbidity: implications for understanding health and health services. Annals of Family Medicine 2009, 7:357-363.

15. German test-version 1 (2000) of the Proactive Coping Inventory PCI. [http://userpage.fu-berlin.de/ health/pcigerman1.htm].

16. Parker $M G$, Thorslund $M$ : Health trends in the elderly population: getting better and getting worse. The Gerontologist 2007, 47:150-158.

17. Starfield B: Threads and yarns: weaving the tapestry of comorbidity. Annals of Family Medicine 2006, 4:101-103.

18. Gesundheit im Alter. [http://www.gesundheitsforschung-bmbf.de/de/1958. php].

19. Autonomy Despite Multimorbidity. [http://www.ama-consortium.de/indexe.html].

20. Kurth BM, Kamtsiuris $P$, Holling $H$, Schlaud M, Dolle R, Ellert $U$, Kahl $H$ Knopf $H$, Lange $M$, Mensink GB, et al: The challenge of comprehensively mapping children's health in a nation-wide health survey: design of the German KiGGS-Study. BMC Public Health 2008, 8:196.

21. Kohler M, Rieck A, Broch S: Methode und Design des telefonischen Gesundheitssurvey 2003. Bundesgesundheitsblatt Gesundheitsforschung Gesundheitsschutz 2005, 48:1224-1230.

22. Häder S, Gabler S: Ein neues Stichprobendesign für telefonische Umfragen in Deutschland. (A new random sampling design for telephone surveys in Germany). In Telefonstichproben in Deutschland (Telephone random sampling in Germany). Edited by: Gabler S, Häder S, Hoffmeyer-Zlotnik JHP. Opladen: Westdeutscher Verlag; 1998:69-88.

23. Bundesweiter Telefongesundheitssurvey (2. Welle - GSTel04). [http:// www.rki.de/cln_169/nn_201174/DE/Content/GBE/Erhebungen/ Gesundheitsurveys/Geda/Cati04_inhalt.html].

24. Bundesweiter Telefongesundheitssurvey (4. Welle - GSTel06). [http:// www.rki.de/CIn_169/nn_201174/DE/Content/GBE/Erhebungen/ Gesundheitsurveys/Geda/Cati06 inhalt.html].

25. Bisherige Telefonsurveys am RKI (GSTel 03-07). [http://www.rki.de/ Cln_151/nn_201180/DE/Content/GBE/Erhebungen/Gesundheitsurveys/Geda/ Bisherige tel survey inhalt.html? nnn=true].

26. Beinhoff $\bar{U}$, Hilbert $V$, Bittner D, Grön $G$, Riepe MW: Screening for cognitive impairment: A triage for outpatient care. Dementia and Geriatric Cognitive Disorders 2005, 20:278-285.
27. Podsiadlo D, Richardson S: The timed "Up \& Go": a test of basic functional mobility for frail elderly persons. Journal of the American Geriatric Society 1991, 39:142-148.

28. Guralnik JM, Ferrucci L, Simonsick EM, Salive ME, Wallace RB: Lowerextremity function in persons over the age of 70 years as a predictor of subsequent disability. New England Journal of Medicine 1995, 332:556-561.

29. Guralnik JM, Simonsick EM, Ferrucci L, Glynn RJ, Berkman LF, Blazer DG Scherr PA, Wallace RB: A short physical performance battery assessing lower extremity function: association with self-reported disability and prediction of mortality and nursing home admission. Journal of Gerontology 1994, 49:M85-94

30. Bellach BM, Knopf H, Thefeld W: The German Health Survey 1997/98. Gesundheitswesen 1998, 60(Suppl 2):59-68.

31. Robine JM, Jagger C, Euro RG: Creating a coherent set of indicators to monitor health across Europe: the Euro-REVES 2 project. European Journal of Public Health 2003, 13(Suppl 3):6-14.

32. European Health Interview Survey (EHIS) Questionnaire. [http://ec.europa. eu/health/ph_information/implement/wp/systems/docs/ ev_20070315_ehis_en.pdf].

33. Kroenke K, Spitzer RL, Williams JB: The PHQ-9: validity of a brief depression severity measure. Journal of General Internal Medicine 2001, 16:606-613.

34. Löwe B, Spitzer RL, Zipfel S, Herzog W: PRIME MD Patient Health Questionnaire (PHQ). 2 edition. Karlsruhe: Pfizer; 2002

35. Lamb SE, Jorstad-Stein EC, Hauer K, Becker C: Development of a common outcome data set for fall injury prevention trials: the Prevention of Falls Network Europe consensus. Journal of the American Geriatric Society 2005, 53:1618-1622.

36. Diener E, Emmons RA, Larsen RJ, Griffin S: The Satisfaction with Life Scale. Journal of Personality Assessment 1985, 49:71-75.

37. Holzhausen M, Kuhlmey A, Martus P: Individualized measurement of quality of life in older adults: development and pilot testing of a new tool. European Journal of Ageing 2010, 7:201-211.

38. Thompson ER: Development and validation of an internationally reliable short-form of the positive and negative affect schedule (PANAS). Journal of Cross-Cultural Psychology 2007, 38:227-242.

39. Krohne HW, Egloff B, Kohlmann CW, Tausch A: Untersuchungen mit einer deutschen Version der "Positive and Negative Affect Schedule" (PANAS). Diagnostica 1996, 42:139-156.

40. Greiner W, Weijnen T, Nieuwenhuizen M, Oppe S, Badia X, Busschbach J, Buxton MJ, Dolan P, Kind P, Krabbe $P$, et al: A single European currency for EQ-5D health states. Results from a six-country study. European Journal of Health Economics 2003, 4:222-231.

41. von der Schulenburg JM, Claes C, Greiner W, Uber A: Die deutsche Version des EuroQol-Fragebogens. Zeitschrift für Gesundheitswissenschaften 1998, 6:3-20

42. Morfeld M, Bullinger M, Nantke J, Brahler E: The version 2.0 of the SF-36 Health Survey: results of a population-representative study. Sozial- und Praventivmedizin 2005, 50:292-300.

43. Bullinger $M$, Kirchberger I, Ware J: Der deutsche SF-36 Health Survey, Übersetzung und psychometrische Testung eines krankheitsübergreifenden Instrumentes zur Erfassung der gesundheitsbezogenen Lebensqualität. Zeitschrift für Gesundheitswissenschaften 1995, 1:21-36.

44. Die zweite Welle des Alterssurveys - Erhebungsdesign und Instrumente. [http://www.dza.de/fileadmin/dza/pdf/Alterssurvey Instrumente.pdf].

45. Katz S, Ford AB, Moskowitz RW, Jackson BA, Jaffe MW: Studies of illness in the aged. The index of ADL: a standardized measure of biological and psychosocial functioning. Journal of the American Medical Association 1963, 185:914-919.

46. Katz S, Down TD, Cash HR, Grotz RC: Progress in development of the index of ADL. The Gerontologist 1970, 10:20-30.

47. Lawton MP, Brody EM: Assessment of older people: self-maintaining and instrumental activities of daily living. The Gerontologist 1969, 9:179-186.

48. Lawton MP: The functional assessment of elderly people. Journal of the American Geriatric Society 1971, 19:465-481.

49. Wahrgenommene Autonomie im Alter (WAA). [http://userpage.fu-berlin. de/ health/autonomie.htm].

50. SOEP 2007 Methodenbericht. [http://www.diw.de/documents/ dokumentenarchiv/17/diw 01.c.333740.de/meth_2007.pdf]. 
51. Schenk L, Bau AM, Borde T, Butler J, Lampert T, Neuhauser H, Razum O, Weilandt C: A basic set of indicators for mapping migrant status. Recommendations for epidemiological practice. Bundesgesundheitsblatt Gesundheitsforschung Gesundheitsschutz 2006, 49:853-860.

52. Adler G, Tremmel S, Brassen S, Scheib A: Soziale Situation und Lebenszufriedenheit im Alter. Zeitschrift für Gerontologie und Geriatrie 2000, 33:210-216.

53. Schulz U, Schwarzer R: Soziale Unterstützung bei der Krankheitsbewältigung: Die Berliner Social Support Skalen (BSSS). Diagnostica 2003, 49:73-82.

54. Anamnesebogen zur Bestimmung des Ernährungszustandes Älterer Menschen. MNA Mini Nutritional Assessment. [http://www.mna-elderly. com/forms/MNA_german.pdf].

55. Bush K, Kivlahan DR, McDonell MB, Fihn SD, Bradley KA: The AUDIT alcohol consumption questions (AUDIT-C): an effective brief screening test for problem drinking. Ambulatory Care Quality Improvement Project (ACQUIP). Alcohol Use Disorders Identification Test. Archives of Internal Medicine 1998, 158:1789-1795.

56. Wetterling T, Veltrup C: Diagnostik und Therapie von Alkoholproblemen Berlin: Springer; 1997.

57. Gossop M, Griffiths P, Powis B, Strang J: Severity of dependence and route of administration of heroin, cocaine and amphetamines. British Journal of Addiction 1992, 87:1527-1536.

58. Bischof G, John U, Rumpf HJ: Assessment of addiction to psychotropic medications. Deutsche medizinische Wochenschrift 2009, 134:2397-2398.

59. Holmes TH, Rahe RH: The Social Readjustment Rating Scale. Journal of Psychosomatic Research 1967, 11:213-218.

60. Buschke H, Kuslansky G, Katz M, Stewart WF, Sliwinski MJ, Eckholdt HM, Lipton RB: Screening for dementia with the Memory Impairment Screen. Neurology 1999, 52:231-238

61. Lipton RB, Katz MJ, Kuslansky G, Sliwinski MJ, Stewart WF, Verghese J, Crystal HA, Buschke H: Screening for dementia by telephone using the Memory Impairment Screen. Journal of the American Geriatrics Society 2003, 51:1382-1390.

62. Morris JC, Heyman A, Mohs RC, Hughes JP, van Belle G, Fillenbaum G, Mellits ED, Clark C: The Consortium to Establish a Registry for Alzheimer's Disease (CERAD). Part I. Clinical and neuropsychological assessment of Alzheimer's disease. Neurology 1989, 39:1159-1165.

63. Luck T, Riedel-Heller SG, Wiese B, Stein J, Weyerer S, Werle J, Kaduszkiewicz H, Wagner M, Mosch E, Zimmermann T, et al: CERAD-NP battery: Age-, gender- and education-specific reference values for selected subtests. Results of the German Study on Ageing, Cognition and Dementia in Primary Care Patients (AgeCoDe). Zeitschrift für Gerontologie und Geriatrie 2009, 42:372-384.

64. Wechsler D: WAIS-III/WMS-III technical manual San Antonio, TX: The Psychological Corporation; 1997.

65. Rapp MA, Reischies FM: Attention and executive control predict Alzheimer disease in late life: results from the Berlin Aging Study (BASE). American Journal of Geriatric Psychiatry 2005, 13:134-141.

66. Rosen WG, Mohs RC, Davis KL: A new rating scale for Alzheimer's disease. American Journal of Psychiatry 1984, 141:1356-1364.

67. Hank K, Jurges H, Schupp J, Wagner GG: Isometric grip strength and social gerontological research: results and analytic potentials of SHARE and SOEP. Zeitschrift für Gerontologie und Geriatrie 2009, 42(2):117-26.

68. Mohd Hairi F, Mackenbach JP, Andersen-Ranberg K, Avendano M: Does socio-economic status predict grip strength in older Europeans? Results from the SHARE study in non-institutionalised men and women aged 50 +. Journal of Epidemiology and Community Health 2010, 64(9):829-37.

\section{Pre-publication history}

The pre-publication history for this paper can be accessed here: http://www.biomedcentral.com/1472-6963/11/47/prepub

\section{doi:10.1186/1472-6963-11-47}

Cite this article as: Holzhausen et al:: Operationalizing multimorbidity and autonomy for health services research in aging populations - the OMAHA study. BMC Health Services Research 2011 11:47.

\section{Submit your next manuscript to BioMed Central and take full advantage of:}

- Convenient online submission

- Thorough peer review

- No space constraints or color figure charges

- Immediate publication on acceptance

- Inclusion in PubMed, CAS, Scopus and Google Scholar

- Research which is freely available for redistribution

Submit your manuscript at www.biomedcentral.com/submit
Ciomed Central 